\title{
Adsorption of 1,2-dichloropropane from aqueous solution
}

\author{
${ }^{1}$ Robert Pełech, Eugeniusz Milchert \\ Szczecin University of Technology, Institute of Chemical Organic Technology, ul. Pulaskiego 10, 70-322 Szczecin, Poland \\ ${ }^{1}$ Corresponding author: ul. Pułaskiego 10, 70-322 Szczecin, Poland, e-mail: Robert.Pelech@ps.pl, tel. (+48 91$) 4494016$
}

In this study dependences of the adsorption equilibrium of 1,2-dichloropropane in aqueous solution for six activated carbons (A, AG, AG5, DTO, WD-ekstra, CWZ-22) and four polymeric adsorbents (XE-563, XE572, XE-340, XE-348) were presented. All the adsorption isotherms onto activated carbons were described by the Freundlich equation. To analyze the isotherms on the polymeric adsorbents the Langmuir-Freundlich equation was used. It was found that in the low range of the concentrations the adsorptive properties of the activated carbons are reduced in the following direction DTO $>$ WD-ekstra $>$ CWZ-22 $>A G>A>A G 5$. Reducing the adsorptive properties of the polymeric adsorbents states was carried out in the following order: XE-340> XE-572>XE-563>XE-348. The adsorbents XE-340, XE-572 and XE-563 have much more higher adsorptive properties than the applied activated carbons. Lower adsorptive properties of XE-348 are the result of its high surface polarity.

Keywords: 1,2-dichloropropane, activated carbon, adsorption, polymeric adsorbents, waste.

Presented at VII Conference Wasteless Technologies and Waste Management in Chemical Industry and Agriculture, Międzyzdroje, 12 - 15 June, 2007.

\section{INTRODUCTION}

Chlorinated organic compounds are heavily used in a wide range of industries, and cause the environmental pollution, especially groundwater pollution. For example, the wastewaters which contain 1,2-dichloropropane are discharged from the plant producing propylene oxide in a large amount ${ }^{1}$. With regard to its significant resistance to biodegradation and its carcinogenic and mutagenic properties, removal of 1,2-dichloropropane is purposeful. Therefore, the development of a feasible process of removing the chlorinated organic compounds from groundwater or wastewater is required. The most reliable process for removing these compounds is the adsorption by the activated carbon or synthetic adsorbents ${ }^{2,3}$. The adsorption processes are usually carried out on an industrial scale in the columns packed with adsorbents. ${ }^{4}$. The design of an adsorption column for the removal (and also, frequently, for the recovery of useful chemical) compounds requires knowledge of the adsorption equilibrium. For the adsorption from the solution, the adsorption isotherm is generally represented by the Freundlich equation, an empirical equation ${ }^{2,5}$. A simple and widely used model is the Langmuir equation. Originally the Langmuir model was intended for monolayer adsorption with no interaction between the adsorbed molecules. Thus, its ability to correlate the experimental data is limited. Other models with more parameters and higher correlation accuracy have been proposed. The three-parameter LangmuirFreundlich model serves as an example

In this study, the adsorption capacities of 1,2dichloropropane for six commercial activated carbon and four polymeric adsorbents were investigated.

\section{EXPERIMENTAL}

\section{Adsorption method}

The adsorption isotherms of the DCP were studied by batch adsorption method. All the tests were conducted in capped flasks $\left(240 \mathrm{~cm}^{3}\right)$, by proportioning the DCP stock solution to the activated carbon suspension and mixing on a shaker at the temperature of $293 \mathrm{~K}$. When the adsorption equilibrium was obtained, the concentrations of the DCP in the aqueous solutions were determined. The equilibrium adsorbed amount of DCP per gram of the adsorbent $a(\mathrm{mg} / \mathrm{g})$ was calculated by equation (1)

$a=\frac{V}{m}\left(C_{0}-C_{e}\right)$

where: $C_{0}$ - initial concentration $\left(\mathrm{mg} / \mathrm{dm}^{3}\right), C_{e}$ - equilibrium concentration $\left(\mathrm{mg} / \mathrm{dm}^{3}\right), m$ - adsorbent mass $(\mathrm{g}), V$ - solution volume $\left(\mathrm{dm}^{3}\right)$.

\section{Analytical method}

The concentration of the studied compound was determined chromatographically on a Thermoquest GC $8000^{\text {Top }}$ instrument with a flame ionization detector (FID). The determinations were carried out isothermally at the temperature of $100^{\circ} \mathrm{C}$. A capillary column DB-WAX $(\mathrm{J} \& \mathrm{~W})$ $30 \mathrm{~m} \times 0,5 \mathrm{~mm} \times 0,5 \mu \mathrm{m} 100 \%$ PEG was used.

\section{Materials}

The adsorbents used in these studies were the six activated carbons (A, AG, AG-5, CWZ-22, DTO, WD-ekstra) supplied by GRYFSKAND SA (Poland) and four polymeric adsorbents (XE-563, XE-572, XE-340, XE-348) supplied by Rohm \& Haas (PA). The activated carbons were washed by distilled water to remove fines and then

Table 1. The properties of the activated carbons

\begin{tabular}{|l|c|c|c|c|c|c|}
\hline Adsorbent & A & AG & AG -5 & DTO & CWZ-22 & WD-extra \\
\hline Bulk density $\left(\mathrm{g} / \mathrm{dm}^{3}\right)$ & 504 & $420-480$ & 428 & 415 & $220-260$ & 400 \\
\hline Specific surface area $\left(\mathrm{m}^{2} / \mathrm{g}\right)$ & 739 & 740 & 661 & 943 & 668 & 756 \\
\hline Pore volume $\left(\mathrm{cm}^{3} / \mathrm{g}\right)$ & 0,424 & - & 0,447 & 0,526 & 0,334 & 0,659 \\
\hline Pore volume $<1,5 \mathrm{~nm}\left(\mathrm{~cm}^{3} / \mathrm{g}\right)$ & 0,18 & 0,17 & 0,18 & 0,25 & 0,13 & 0,11 \\
\hline
\end{tabular}


Table 2. The properties of the polymeric adsorben

\begin{tabular}{|c|c|c|c|c|}
\hline Adsorbent & XE-340 & XE-348 & XE-563 & XE-572 \\
\hline Bulk density $\left(\mathrm{g} / \mathrm{dm}^{3}\right)$ & 504 & 660 & 490 & 490 \\
\hline Specific surface area $\left(\mathrm{m}^{2} / \mathrm{g}\right)$ & 400 & 500 & 550 & 1100 \\
\hline Chemical character ${ }^{*}$ & St/DVB & St/DVB & St/DVB & St/DVB \\
\hline Polarity & non polar & polar & non polar & non polar \\
\hline
\end{tabular}

*St/DVB - copolymer styrene/divinylbenzene

were dried in an oven for $24 \mathrm{~h}$ at $110^{\circ} \mathrm{C}$. The properties of the used adsorbents are presented in Tables 1 and 2. 1,2dichloropropane ( $>99 \%$ ) used in these studies was taken from Fluka A.G.

\section{RESULTS AND DISCUSSION}

The adsorption isotherms of the DCP onto the activated carbons are shown in Fig. 1, however the adsorption isotherms of the DCP onto the polymeric adsorbents are shown in Fig. 2.

All the adsorption isotherms were described by the Freundlich equation:

$a=k C_{e}^{n}$

where: $k$ and $n$ are the empirical coefficients of the Freundlich equation.

The coefficients of that equation, together with the correlation coefficient $\left(R^{2}\right)$, were presented in Table 3. It was found that the increase of the parameter $k$ from that equation for the examined carbons may be arranged in the

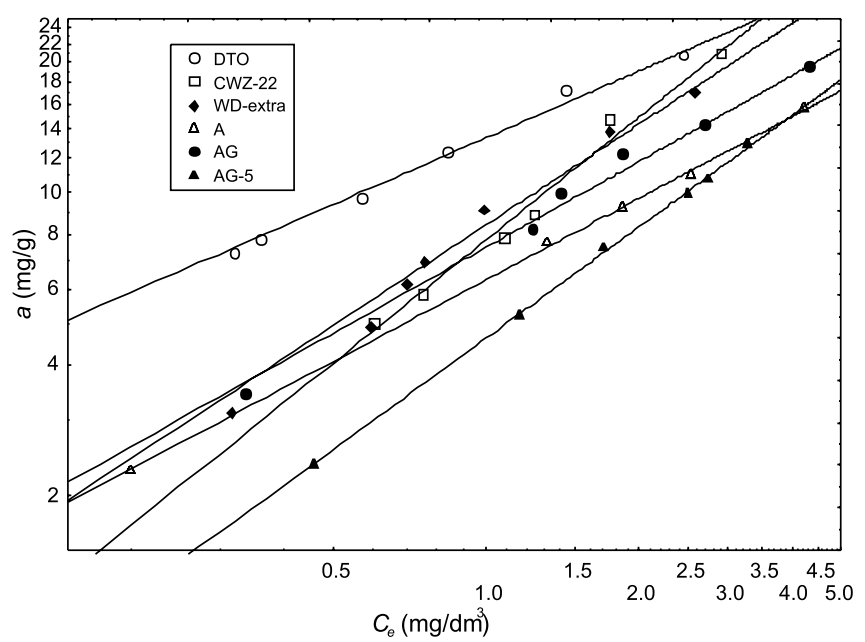

Figure 1. A plot of the linear Freundlich isotherms of DCP on the activated carbons

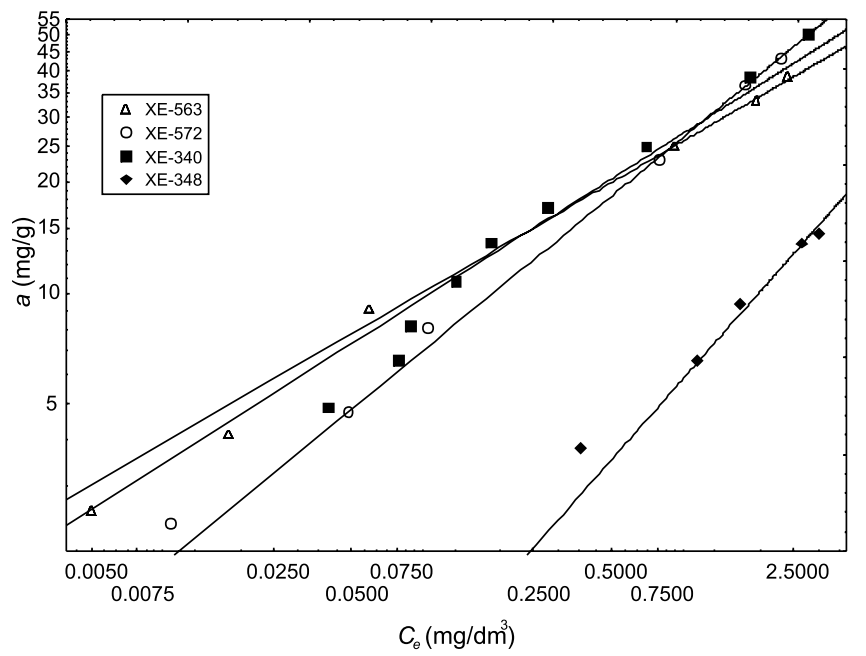

Figure 2. A plot of the linear Freundlich isotherms of DCP on the polymeric adsorbents
Table 3. The coefficients of the Freundlich equation

\begin{tabular}{|l|r|c|c|}
\hline \multicolumn{1}{|c|}{ Adsorbent } & \multicolumn{3}{c|}{ Coefficient } \\
\hline & $k$ & $N$ & $R^{2}$ \\
\hline DTO & 13,369 & 0,516 & 0,99 \\
\hline WD-extra & 8,419 & 0,773 & 0,99 \\
\hline AG & 7,476 & 0,657 & 0,96 \\
\hline A & 6,290 & 0,624 & 0,99 \\
\hline AG-5 & 4,616 & 0,852 & 0,99 \\
\hline CWZ-22 & 7,770 & 0,940 & 0,98 \\
\hline XE-340 & 27,846 & 0,447 & 0,98 \\
\hline XE-572 & 27,367 & 0,579 & 0,97 \\
\hline XE-563 & 26,482 & 0,410 & 0,98 \\
\hline XE-348 & 6,153 & 0,797 & 0,96 \\
\hline
\end{tabular}

following order DTO $>$ WD-ekstra $>$ CWZ$22>A G>A>A G 5$. In the case of the synthetic adsorbents the direction appears in a way: XE-340 $>$ XE-572 $>$ XE$563>$ XE-348. Moreover, for the adsorbents XE-340, XE572 and XE-563 that coefficient exceeds the values obtained for the examined activated carbons. Lower values for XE-348 come from its highest surface polarity, which is in line with Traube law.

The situation looks different for the coefficient $\mathrm{n}$ from the Freundlich equation. For the activated carbons the direction of its increase is given as follows: DTO $<$ A $<$ AG $<$ WD-ekstra $<$ AG- $5<$ CWZ-22, whereas for the resins it is XE-563<XE-340<XE-572<XE-348.

It shows that the DCP concentration in the treated stream affects also the optimal usage of the adsorbent. For low concentrations, the adsorbents with a higher coefficient $k$ from the Freundlich equation achieve a higher amount of adsorption. Though, for the higher concentrations the adsorbents have the higher values of the amount of adsorption with the higher coefficient $n$.

The analysis of the correlation coefficient show that in case of the activated carbons the Freundlich equation describes the sequence of the experimental points very well. In the case of the polymeric adsorbents, the worse fitting of that equation to the experimental points is obtained. Applying the Langmuir equation does not produce any good results, either. To describe those dependence well the triparameter Langmuir-Freundlich equation was used:

$a=a_{m} \frac{b C_{e}^{n_{1}}}{1+b C_{e}^{n_{1}}}$

where: $a_{m}, b, n_{1}$ - coefficients of Langmuir-Freundlich equation.

To determine the parameters of that equation it was rearranged to the linear form given below:

$\frac{1}{a}=\frac{1}{a_{m} b C_{e}^{n_{1}}}+\frac{1}{a_{m}}$

From a linear regression of $1 / a$ versus $1 / C_{e}^{m}$, the values of $b$ and $a_{m}$ can be determined, respectively, from the slope and $\mathrm{Y}$-axis intercept. It needs to be noted that the exponent $n_{l}$ is a fitting parameter by which we can determine the best linear regression for a given system. 


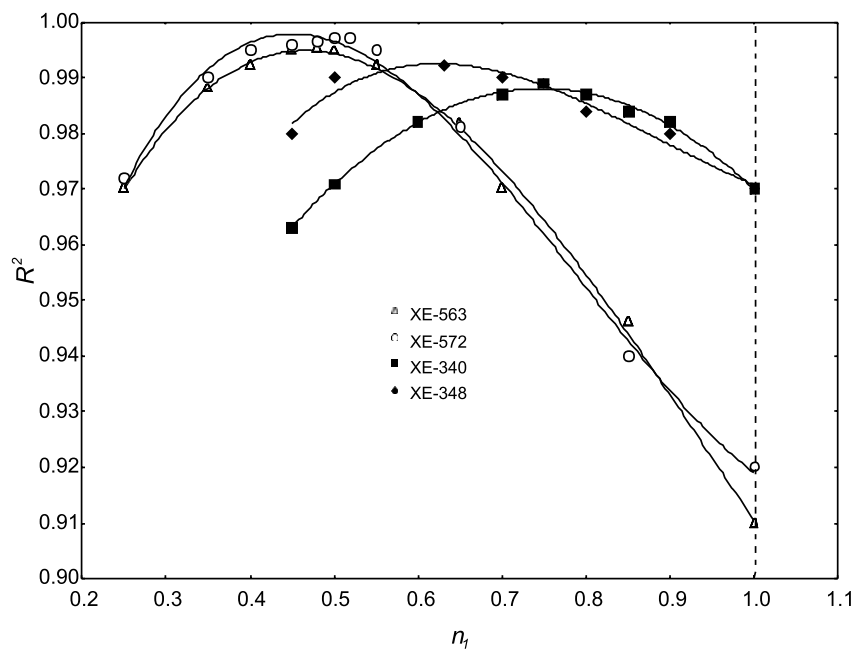

Figure 3. $R^{2}$ from the least square fit versus $n_{1}$ in the study of adsorption isotherms of DCP on the polymeric adsorbents

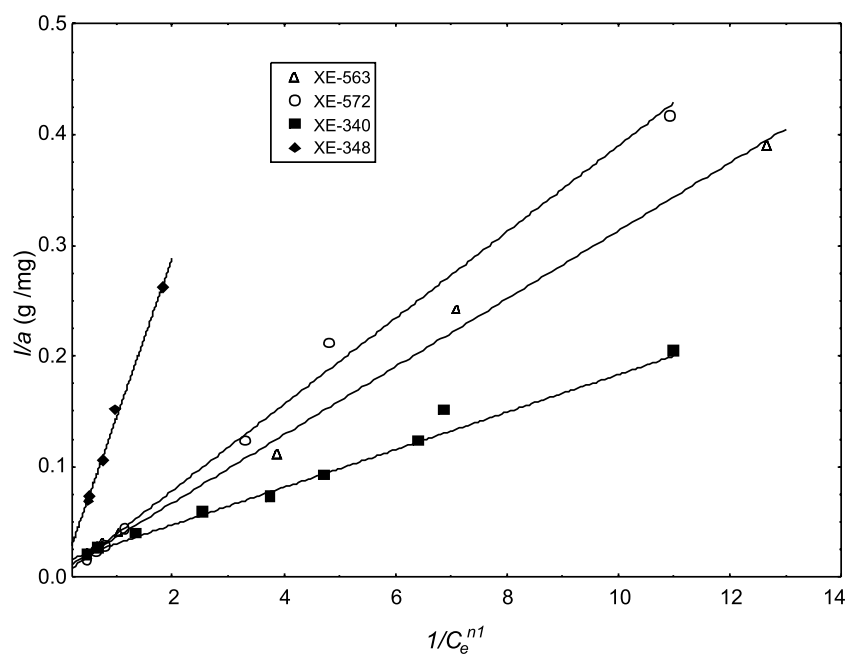

Figure 4. A plot of the linear Langmuir-Freundlich isotherm of DCP on the polymeric adsorbents

In Fig. $3 R^{2}$ versus $n_{1}$, the adsorption of DCP on polymeric adsorbents was shown.

The field of the values corresponding to the Langmuir equation was marked by the broken line. Fig. 4 shows the linear dependence of the Langmuir-Freundlich equation for the systems with polymeric resins for the optimally selected values $n_{1}$. In Table 4 the obtained values of the determined parameters of Langmuir-Freundlich equation were presented.

\section{CONCLUSION}

The DCP adsorption isotherms onto the activated carbons is described well by the Freundlich equation. In the case of the adsorption on the polymeric adsorbents, the Langmuir-Freundlich equation gives better fitting. In both cases the Langmuir equation describes the adsorption isotherms in a poor way. It was found that for the concentration range $>1 \mathrm{mg} / \mathrm{dm}^{3}$ the adsorptive properties are reduced in the following way: DTO $>$ WD-ekstra $>$ CWZ$22>\mathrm{AG}>\mathrm{A}>\mathrm{AG} 5$. In the case of resins the direction is given as follows: XE-340> XE-572>XE-563>XE-348. Moreover, the adsorbents XE-340, XE-572 and XE-563 with their effectiveness exceed the applied activated carbons considerably.
Table 4. The coefficients of the Langmuir-Freundlich equation

\begin{tabular}{|l|c|c|c|}
\hline Adsorbent & $a_{m}$ & $B$ & $n_{1}$ \\
\hline XE-563 & 179.0 & 0.1813 & 0.48 \\
\hline XE-572 & 8923 & 0.0028 & 0.52 \\
\hline XE-348 & 75.75 & 0.7764 & 0.75 \\
\hline XE-340 & 5263 & 0.0013 & 0.63 \\
\hline
\end{tabular}

\section{LITERATURE CITED}

(1) Milchert E.: Technologie produkcji chloropochodnych organicznych. Utylizacja odpadów. WUPS, Szczecin, 1997.

(2) Bembnowska A., Pełech R., Milchert E.: Adsorption from aqueous solutions of chlorinated organic compounds onto activated carbons. J. Colloid Interf. Sci. 2003, 256, 276 $-282$.

(3) Urano K.. Yamamoto E., Tonegawa M., Fujite K.: Adsorption of chlorinated organic compounds on activated carbon from water. Wat. Res. 1991, 25, 1459 - 1464.

(4) Pełech R., Milchert E., Wróbel R.: Adsorption dynamics of chlorinated hydrocarbons from multi-component aqueous solution onto activated carbon. J. Hazard. Mater. 2006, 137, 1479 - 1487.

(5) Urano K., Koichi Y., Nakazawa Y.: Equilibria for adsorption of organic compounds on activated carbons in aqueous solutions. J. Colloid Interf. Sci. 1981, 81, 477 - 485.

(6) Sohn S., Kim D.: Modification of Langmuir isotherm in solution systems-definition and utilization of concentration dependent factor. Chemosphere, 2005, 58, 115 - 123. 